\title{
Seeing Through the Fumes: Technology and Asymmetry in the Anthropocene
}

\author{
Jochem Zwier ${ }^{1}$ D $\cdot$ Vincent Blok ${ }^{2}$
}

Published online: 6 June 2019

(c) The Author(s) 2019

\begin{abstract}
This paper offers a twofold ontological conceptualization of technology in the Anthropocene. On the one hand, we aim to show how the Anthropocene occasions an experience of our inescapable inclusion in the technological structuring of reality that Martin Heidegger associates with cybernetics. On the other hand, by confronting Heidegger's thought on technology with Georges Bataille's consideration of technological existence as economic and averted existence, we will criticize Heidegger's account by arguing that notwithstanding its inescapable inclusion in cybernetics, technology in the Anthropocene itself fosters an experience of what remains excluded. We conclude by indicating how such an experience is relevant for contemporary philosophical investigation of technology.
\end{abstract}

Keywords Anthropocene $\cdot$ Earth $\cdot$ Heidegger $\cdot$ Bataille $\cdot$ Cybernetics $\cdot$ Asymmetry

And Earth, our blood-warm Earth, a shuddering prey

To that frigidity of brainless ray - George Meredith

\section{Introduction}

This paper offers a twofold ontological conceptualization of technology in the Anthropocene. On the one hand, we aim to show how the Anthropocene occasions an experience of our inescapable inclusion in the technological structuring of reality that Martin Heidegger associates with cybernetics. On the other hand, by confronting Heidegger's thought on technology with Georges Bataille's consideration of technological

Jochem Zwier

Jochem.zwier@ru.nl

1 Faculty of Science, Institute for Science in Society, Radboud University Nijmegen, Heyendaalseweg 135, 6525 AJ Nijmegen, The Netherlands

2 Department of Social Sciences; Subdivision Philosophy, Wageningen University and Research, Hollandseweg 1, Wageningen 6706 KN, The Netherlands 
existence as economic and averted existence, we will argue that notwithstanding its inescapable inclusion in cybernetics, technology in the Anthropocene itself fosters an experience of what remains excluded. We conclude by indicating why such an experience is relevant for the contemporary philosophical investigation of technology.

To clarify what is at stake, we will address technology in terms of symmetry and asymmetry. In "The Anthropocene as Cybernetic Phenomenon" section, we begin by interpreting the Anthropocene as a cybernetic phenomenon in Heidegger's sense. Technological existence is thereby rendered ontologically symmetric, meaning that our habitation of the Earth comes to be characterized by what we will discuss as a collective measure (sym-metry) of technological regulation. In "The Anthropocene and the Intrusion of Asymmetry" section, we consider the Anthropocene from an ecological perspective to articulate an asymmetry on the part of the anthropocenic Earth. Subsequently, the "Phenomenon and Asymmetry" section shows how this asymmetry comes to unsettle Heidegger's ontological interpretation of symmetric cybernetics. Put briefly, this means that even though the Anthropocene concretely corresponds to Heidegger's portrayal of the "cybernetic age," it does not entail the therewith associated oblivion of being. Instead, we will develop a critique of Heidegger's consideration of cybernetics by arguing that the peculiar interplay of technology and the Earth gives rise to a concrete experience of being as concealing-unconcealing. To investigate this experience, the "Bataille: Asymmetry and Technology" section introduces a Bataillean reading of technology that flanks but finally strays from Heidegger's interpretation. Situating technology in Bataille's thought on economy and waste allows for an articulation of technological existence as forgetfully diverting from what ontologically constitutes it. While such an articulation of technology resonates with Heidegger's association of cybernetic technology and the oblivion of being, we submit that technology in the Anthropocene comes to be reminded of this forgetful diversion, notably due to the way it relates to the Earth via abundance and waste. We therefore conclude that in the Anthropocene, technology must be understood as ontologically forgetful, but not wholly oblivious, as it fosters - through the fumes of the technological waste named $\mathrm{CO}_{2}-$ a responsivity to what ontologically constitutes technological existence whilst remaining asymmetric to it. Finally, the "Conclusion: the Asymmetric Exposure" section indicates why such a twofold consideration of technology (as symmetric and asymmetric) is relevant for the philosophical questioning of technology in relation to our earthly ecology.

\section{The Anthropocene as Cybernetic Phenomenon}

In this section, we interpret the Anthropocene as a cybernetic phenomenon, thereby using Heidegger's considerations of phenomenology and cybernetics as a guide.

The Anthropocene is commonly understood as the epoch in which the technological activity of industrialized humanity becomes the dominant factor shaping the Earth and its associated life-supporting systems (Steffen et al. 2007). Supplementing the Holocene, where the relatively warm climate was considered to be the critical geological factor (Crutzen 2002; Fagan 2004; Dumanoski 2009), the Anthropocene places anthropic technological activity in the center, thus marking the time in which 
"natural and human forces [are] intertwined, so that the fate of the one determines the fate of the other" (Zalasiewicz et al. 2010: 2231).

As Hamilton, Bonneuil, and Gemmene note, the concept of the Anthropocene is not isolated to the scientific fields of climate science, geology, and earth-system science, but moves beyond these fields insofar as it more generally "represents the ground-breaking attempt to think together earth processes, life, [and] human enterprise (...) into a totalizing framework" (Hamilton et al. 2015: 2). This convergence of human enterprise and other earthly processes is philosophically relevant because it renders them symmetric, meaning that both appear in the same register of geoforces whose operation constitutes the earth-system. By implication, human rational thought is not merely considered to appear on Earth as a manifestation of something superlunary or transcendent, but primarily appears as Earth, which is to say as one of many earth-shaping geo-forces, albeit one of considerable magnitude (see Zwier and Blok 2017). The magnitude of the rational geo-force called humanity becomes particularly patent in its techno-industrial interlocking with other earthly processes, for instance the ones that engender fossil fuels (the residue of antecedent geo-forces such as organic life compressed via plate tectonics). By way of this interlocking of geo-forces, the human geo-force currently takes the stage as the dominant earthshaping force amongst many (see Crutzen 2002; Steffen et al. 2007, 2011a, b).

The Anthropocenic symmetry between thought and other earthly processes is philosophically relevant because it suggests that theoretical thought can no longer assume an isolated perspective that merely observes the configuration of geo-forces as an object, but is itself always already implicated or included in this configuration. Such inclusivity prompts an interpretation of the Anthropocene as a phenomenon to be questioned phenomenologically. ${ }^{1}$ Following the work of Martin Heidegger, a phenomenon never stands over against us as thing or object, but concerns the relation that we always already enact in our encounter with things (see Heidegger 2004; see Zwier et al. 2016). Heidegger famously exemplifies this relationality when he shows how a theoretical perspective on a hammer (considered as material object with particular weight, strength etc.) already enacts a specific relation by means of which the hammer can appear as a theoretical, "present-at-hand" object (Heidegger 2008: 93, 95). Such a theorizing relation is not universal but specific: in using a hammer, one does not encounter it as a theoretical object, but rather enacts a kind of relation by which the hammer appears "ready-to-hand" (2008: 95-102), meaning that it withdraws in favor of the project that is to be hammered out. Although we can relate to things in various ways, the crucial phenomenological point is that we are always already and inescapably included in a relation. Such inclusion is inescapable because of the following reason: although our way of encountering a hammer can itself become the object of analysis (as the above example illustrates), this can only be done by enacting a relation in which this particular encounter itself

\footnotetext{
1 The concept of the Anthropocene has come to be interpreted in a vast variety of ways. Instead of exhaustively covering its many (critical and eulogistic) conceptualizations, we here limit ourselves to an interpretation of the Anthropocene as phenomenon. For a good overview of the discourse on the Anthropocene, see Lorimer (2016).
} 
appears as theoretical object to be analyzed. This then means that we are always already included in a relation between being and thinking, whether this concerns the 'embodied' kind of thinking enacted in praxis (using a hammer) or a more 'abstract' theoretical thinking (studying the hammer as object, or analyzing ways of encountering a hammer). The phenomenon concerns this inclusive relation between being and thinking. It is thereby not itself situated on the ontic level of beings or objects that we find in front of us, but must be understood ontologically, as an inescapable structuring of our encounter with things. Now, the Anthropocene attests to a similar inescapable inclusivity, given how human (practical and theoretical) activity is here considered to be inevitably implicated in a play of geo-forces. This suggests that the Anthropocene can be understood as phenomenon (see Zwier and Blok 2017).

Questioning the phenomenon of the Anthropocene accordingly means questioning the character of its inclusive relationality. We propose to call this relationality cybernetic. This follows Heidegger's interpretation of cybernetics as a "foundational" or "fundamental science [Grundwissenschaft]" (Heidegger 1972: 58). ${ }^{2}$ For Heidegger, cybernetics is not one particular scientific discipline apropos a specific domain of objects at the ontic level of specific beings (technological, organic, social etc.), but is ontological in that it concerns the relation between being and thinking that already "defines and steers" (1972: 58, translation modified) the objective sciences, meaning that it structures the way in which objects are encountered and how propositions regarding such objects are made and evaluated. He calls this ontological relationality cybernetic because being and scientific thinking couple in an operative feedback-loop: in the same way that an anti-aircraft cannon constantly feeds-back information pertaining to the flightpath of an aircraft into its actuators (speed of rotation, angle of barrel etc.) to constitute an adaptive system, the sciences feed-back propositions, categories, hypotheses, and (experimental) results into a functioning whole, constantly adapting or discarding dysfunctional elements, for instance via a process of falsification (see Heidegger 2001: 91-92, 1972: 58-59). Our hypothesis is that the phenomenon of the Anthropocene involves such a cybernetic relation between being and thinking, whilst provoking a concrete experience of our inclusion in this cybernetic relationality. As such, we submit that the Anthropocene can be characterized as cybernetic phenomenon. To develop this hypothesis, we begin by analyzing both sides of the relation between being and thinking, which in turn sheds light on the phenomenological implications pertaining to this relation itself.

On the side of being, the anthropocenic objective sciences (most notably earthsystem science) consider the being in question — the Earth—as earth-system. This system has a cybernetic character insofar as various functional elements (temperature, $\mathrm{pH}$, chemical composition of the atmosphere, ecosystems, and notably human activity) couple in a feedback-loop which regulates the conditions of the

\footnotetext{
${ }^{2}$ Given the focus of this paper on phenomenology, technology, and the Anthropocene, our discussion of cybernetics will be limited to Heidegger's interpretation of cybernetics as "foundational science". The broader question regarding the relation between Heidegger's cybernetics and other interpretations is therefore left open. For an instructive overview of such interpretations, see Hayles (1999).
} 
planet understood as integral system. Steffen, Crutzen, and McNeill accordingly define the earth-system as

the suite of interacting physical, chemical and biological global-scale cycles (...) and energy fluxes that provide the life-support system for life at the surface of the planet. [A] critical feature is that forcings and feedbacks within the Earth System are as important as external drivers of change, such as the flux of energy from the sun. [The] Earth System includes humans, our societies, and our activities; thus, humans are not an outside force perturbing an otherwise natural system but rather an integral and interacting part of the Earth System itself. (Steffen et al. 2007: 615; see Hamilton 2016: 94)

The being called the earth system thus appears as a cybernetic system, which integrates human beings as one of its many regulatory elements. Be that as it may, this description of a particular cybernetic being does not yet lend credence to our hypothesis that the Anthropocene concerns a cybernetic relation between being and thinking in an ontological sense. We therefore turn to the side of thinking.

It is noteworthy that anthropocenic scientific thought is not merely about some cybernetic being called the earth-system and its dynamic configuration of geoforces. Rather, scientific thought is itself already included in a cybernetic encounter with this cybernetic being, given how it is oriented towards regulation of the human habitat. Science has not only disclosed how the Anthropocene signalsmost eminently and alarmingly via global warming - the advent of an earthly regime that may well be uninhabitable for humanity, but immediately responds to this by mobilizing scientific knowledge about the earth-system to ward off such a regime (see Hamilton et al. 2015: 4; Baskin 2015: 13; Clark 2011). Instances of this include Crutzen's aim to "guide society towards environmentally sustainable management during the era of the Anthropocene" (2002: 23), the envisaged task to "steer nature's course symbiotically" (Crutzen and Schwägerl 2011), or the general idea of "Planetary Stewardship" (Steffen et al. 2011a, b), whether via radical geo-engineering or other (perhaps more conservative) ways of technologically regulating the planet (see Lorimer 2016; see Zwier and Blok 2017; Lynas 2011). As Jeremy Baskin sums up:

In almost all of the major accounts of the concept it is assumed that [the Anthropocene] requires a trinity of techniques: clear management of the Earth and Earth-systems, guided by experts (and scientists/engineers in particular), using the most advanced technology possible (including large-scale technology). (2015: 20)

This regulative response to global warming indicates how scientific thought is not merely about the cybernetic being called the earth-system, but itself immediately and cybernetically feeds back into this system to regulate thermal parameters that are presently witnessed to drift towards fatal levels. Such a focus on regulation is not limited to eco-modernist programs of planetary engineering. For instance, the socio-ecological approach of "Resilience Thinking" (Walker and Salt 2006) is critical of a "command-and-control approach" (11) that tends to place human 
management outside the ecological system. At the same time, whilst explicitly acknowledging and including itself in the interlinking of social and natural systems (8), resilience thinking expressly considers such interlinking in terms of cybernetic regulation and feedback. This is evidenced by its basic concepts, where, for example, resilience itself is understood as "the ability of a system to absorb disturbance and still retain its basic function" (1), or where "thresholds" take account of how systems have "more than one kind of stable state ... with different feedbacks between its component parts" (11). ${ }^{3}$ Generally then, with regards to the relation between being and thinking, such emphasis on regulation and feedback makes clear that scientific thought not only encounters the earth-system as a cybernetic being or system at the ontic level, but that this encounter is itself already "defined and steered" by cybernetics at an ontological level.

Yet what is more, this cybernetic character is not limited to scientific thought visà-vis the earth-system, but equally envelops the mundane thinking that we enact in, for example, having a cup of coffee. Indeed, the phenomenon of the Anthropocene precisely and quite literally renders a cup of coffee mundane insofar as its earthly character becomes pronounced (ontologically, not aromatically). In the same way that we no longer can have routine conversations about the weather without having global warming intrude upon the conversation (Morton 2013: 99), neither can we have a cup of coffee that is not shadowed by its earthly trace, e.g., a carbon-footprint related to its production, shipping, brewing, etc., and which cannot be dissociated from a warming earth-system. Of course, this earthly character is not always obtrusive: we do not experience it when stopping by the coffee machine before rushing into a meeting. Yet when it does come to the fore-for instance when the emptied beaker made out of $100 \%$ biodegradable materials catches our eye during a tedious meeting ${ }^{4}$ - it not only reveals our preceding activity of drinking coffee as feeding back into the earth-system, but further makes clear that this feedback is unavoidable: opting for ecologically certified coffee that includes emission compensation precisely takes account of such feedback. The takeaway here is not some normative vilification of coffee, but a phenomenological indication of how the cybernetic character of the Anthropocene does not merely concern the relation between being and scientific thinking, but likewise envelops the relation between being and the mundane, everyday thinking involved in brewing, ordering, or drinking a cup of coffee.

In this way, the Anthropocene can be said to render Heidegger's arguably rather abstract ontological interpretation of cybernetics concrete, as it manifests how we are inescapably included in a relationality that can be phenomenologically characterized in terms of cybernetic, regulative steering. ${ }^{5}$ For Heidegger, cybernetics means that

\footnotetext{
${ }^{3}$ We thank one of the anonymous reviewers for bringing the approach of resilience thinking to our attention.

4 We will return to the question of waste (here: the used-up coffee container) in the "Bataille: Asymmetry and Technology" and "Conclusion: Asymmetric Exposure" sections.

5 Heidegger himself links cybernetics and phenomenology when he discusses cybernetic "steering" as "phenomenon" in the seminars on Heraclitus, fragment 64 (see Heidegger and Fink 1979: 10-14).
} 
The world-relations of humans and with them the collective societal existence of humans, are enclosed in the hegemonic domain of cybernetic science. (Heidegger 1983: 145) 6

In the Anthropocene, we can experience this "enclosure" in a concrete way insofar as we find ourselves part and parcel of a warming globe that must be regulated if it is to remain habitable. If the abovementioned coffee merely offers an easily overlooked glimpse, more blatant examples include starting the ignition of a car after refuelling (where feed-back into a thermally drifting earth-system increasingly becomes a burning concern), or proudly studying the yields of one's rooftop solar array to record the "kg's of $\mathrm{CO}_{2}$-emissions saved". The experience here is how, just as we cannot step outside our warming globe, neither can we escape relating to this globe as an earth-system needing to be regulated in one way or another. As such, we can say that the Anthropocene both concurs with Heidegger's interpretation of cybernetics and concomitantly offers a concretisation of what he articulates as our being "enclosed" (Heidegger 1983: 145) in a cybernetic relationality. ${ }^{7}$

\section{The Anthropocene and the Intrusion of Asymmetry}

The previous section took notice of what we can call the symmetry of the Anthropocene. Understood according to its colloquial meaning, such symmetry denotes a qualitative similarity, where humanity registers as one of many similar geo-forces that make up and shape the earth-system. Yet further, understood phenomenologically, this symmetry not only betokens the ontic domain of beings (such as geoforces) but the ontological relation between being and thinking as well: if, as argued, the phenomenon of the Anthropocene implies that earthly beings (including ourselves as scientists, coffee drinkers, car refuelers, etc.) appear included in a cybernetic relationality, then this relationality is itself symmetric inasmuch as it is characterized by an inexorable-paraphrasing Heidegger: "enclosing"-collective measure, a sym-metry of regulative steering. Now, by foregrounding the Earth, the present section contrasts the symmetry of the Anthropocene by introducing an Earthly asymmetry.

Whatever one makes of it, the Anthropocene always obviously concerns the Earth. We proffer, however, that the above interpretation of the Anthropocene as cybernetic phenomenon engenders a specific, twofold understanding of the Earth, namely as symmetric oikos and asymmetric intrusion.

As to the first, we have argued that our current encounter with things takes place as Earth inasmuch as the regulative steering enacted by the geo-force called

\footnotetext{
6 As noted, "cybernetic science" must here be ontologically understood as "foundational science".

7 This also shows how Heidegger's interpretation of cybernetics can be read as a different articulation of his questioning of technology (see Heidegger 1977). In "The End of Philosophy and the Task of Thinking," Heidegger writes: "[The] fundamental characteristic of [the] scientific attitude is its cybernetic, that is, technological character" (Heidegger 1972: 58). For an analysis of Heidegger's questioning of technology in relation to the Anthropocene, see Zwier and Blok (2017); Williston (2017).
} 
humanity inheres in an Earthly interplay of many symmetric geo-forces (notably including the interplay of geo-forces such as plate tectonics and organic life that engender fossil fuels on the one hand, and their technological, exploitative regulation by the human geo-force and its combustion engines on the other). Be that as it may, such symmetric encounters evidently take place on Earth. The latter can thereby be understood as the habitat or oikos that, as it were, provides the stage upon which the interplay of geo-forces unfolds. This oikos is symmetric in the ontic sense of housing a vast variety of symmetric geo-forces, but is also symmetric in an ontological sense that concerns the character of our habitation of this Earthly oikos, where being and thinking (whether scientific or mundane, see "The Anthropocene as Cybernetic Phenomenon" section) couple in a regulative feedback-loop and thus adhere to the collective measure (sym-metry) of cybernetic regulation.

Besides the Earth as symmetric oikos, however, the Anthropocene also involves an asymmetry between oikos and Earth. This comes into view as the flipside of symmetrically understanding humanity as a geo-force: while the current dominance of the anthropic geo-force may validate its very own epochal nameplate, it becomes equally evident that this dominance is not its own Munchhausen-like doing, but is conditioned by the Earth. Not only does our geo-forcefulness hinge on the Earth granting us access to its vast depot of fossil fuels, but the very existence of our now planetary oikos turns out to be contingently premised on the earth-system going through a (Holocenic-Anthropocenic) period of relative climatic stability (see Szersynski 2012: 168). And at this juncture, global warming makes its dreaded entrance, not only as the consequence of the infernal coupling of the anthropic geo-force and fossil fuels (see Clark and Yusoff 2014), but primarily as compelling a concrete experience of what earth-system science and geology have long since known objectively, namely that the Earthly stability that supports our oikos and which we take for granted, is no longer self-evidently granted, and turns out to be an exception to the rule of a deeply unstable, constantly fluctuating and capricious Earth (see Clark 2011; McGuire 2013; Zwier and Blok 2017). This then demonstrates how in the Anthropocene, the cybernetic regulation of our habitat not only belongs to the Earth (here understood as the symmetric oikos upon which the interplay of geo-forces such as humans and fossil-fuels transpires), but is conjointly pitted against the Earth insofar as we find it withdrawing its stable support. In correspondingly experiencing the necessity to regulate against such withdrawal by way of some form of technological regulation, we both encounter and counter the intrusion of an Earthly regime that transcends, exceeds, i.e., remains asymmetric to our oikos. In short, in the Anthropocene, we do not merely inhabit the Earth (as symmetric oikos), but in so doing (en)counter the intrusion of the asymmetric Earth. ${ }^{8}$

\footnotetext{
${ }^{8}$ What we here articulate as the intrusion of the asymmetric Earth resonates with what Isabelle Stengers has called "the intrusion of Gaia," implying "the need to take into account a protagonist that will never recede into the background, and whose the [sic] stability 'we' will never again be able to take for granted (2015: 137). Given the complicated nature of the current discourse on Gaia (see Stengers 2009; Latour 2017; Crutzen 2004) further elaboration of this protagonist would exceed the scope of this paper.
} 
This oiko-logical interpretation of the Anthropocene thus gives rise to a twofold consideration of the Earth as symmetric oikos and asymmetric intrusion. This consideration roots in what at first appears as a singularly ontic interpretation of a being called the Earth. It is open to question, however, whether the intrusion of the asymmetric Earth is limited to the ontic domain. The question that therefore follows concerns the implications of asymmetry for cybernetic symmetry.

\section{Phenomenon and Asymmetry}

In responding to the question raised at the end of the previous section, the hypothesis developed here is that the intrusion of asymmetry in the Anthropocene engenders a reorientation of Heidegger's ontological interpretation of cybernetics. We submit that such a reorientation is significant for philosophy of technology, because it allows for a reconsideration of Heidegger's identification of technology and the oblivion of being. To clarify this reorientation, it is fist necessary to elucidate two additional points of reference that orient Heidegger's ontological interpretation of cybernetics ("Heidegger: Cybernetics and Oblivion" section), and subsequently confront these with the Anthropocene ("Cybernetics and the Anthropocene" section). Having already discussed the enclosure of cybernetics ("The Anthropocene as Cybernetic Phenomenon" section), we now turn to its unidirectionality and occlusion.

\section{Heidegger: Cybernetics and Oblivion}

In characterizing the relation between being and thinking, cybernetics structures the way in which beings are encountered, namely according to a collective measure, a sym-metry of regulation. For Heidegger, such structuring is unidirectional, meaning that our (technological) interactions with the world at the ontic level neither affect nor escape the ontological relationality in which they are always already included. We have heard Heidegger state that:

The world-relations of humans and with them the collective societal existence of humans, are enclosed in the hegemonic domain of cybernetic science. (Heidegger 1983: 145)

He further says of cybernetics that

[its] most expansive feedback-loop encompasses the interrelation of man and world (...) [and its] occlusion [Verschlossenheit] can never be disjointed by human beings (...) not by way and means of scientific-technical planning and making. (Heidegger 1983: 145-146)

On the one hand, these fragments indicate Heidegger's unidirectional relating of being and beings. As a "foundational science" (Heidegger 1972: 58; see §1), cybernetics is not some generalization or categorisation that abstracts from the cybernetic beings encountered in the world (e.g., cybernetic systems, theories, or human operations), but is rather understood as the "hegemonic domain" that already "encloses" 
and "encompasses" every relation to the world and worldly beings. What is more, inasmuch as our encounter and interaction with the ontic world of beings, for instance our "scientific-technical planning and making," is already "encompassed by" the ontological relation between being and thinking that structures this encounter, the ontic domain only responds to ontological cybernetics, whilst never reshaping or "disjointing" it. Put succinctly, ontological cybernetics structures the ontic world of beings, but never vice versa. We can refer to this the unidirectionality of Heidegger's interpretation of cybernetics. ${ }^{9}$

On the other hand, the previous quotations not only make clear how cybernetics is ontologically unidirectional and enclosing, but further indicate that this entails an occlusion [Verschlossenheit]. This occlusion is considered as an "occlusion vis-à-vis the destining [Geschick]" (Heidegger 1983: 146). Explained in phenomenological terms, such destining can be understood as the characterization of the ontological relationality in which we are always already included, and which structures the way in which we encounter things. For Heidegger, such structuring takes on different configurations throughout the "history of being" (Heidegger 1999) of the Western philosophical tradition. Where, for example, antique philosophy encountered a tree as a sublunary, perishable instance of a superlunary, eternal idea, and where medieval philosophy encountered the same tree as ens creatum in a divinely instituted order of things, today, in light of global warming, we encounter this tree cybernetically, as a carbon-source or carbon-sink to be regulated (see Zwier and Blok 2017). ${ }^{10}$ Leaving aside further analysis of these "destinings" and their coherence, it presently suffices to emphasize how such destining belongs in what Heidegger calls the concealing-unconcealing of being (Heidegger 1998a). This means that in the emergence of a destining (unconcealment), the possibility for a different destining remains withdrawn (concealment).

Now, Heidegger considers cybernetics as an ontological destining in the above illustrated sense, but its "occlusion" entails that this destining itself is forgotten. This is to say that cybernetics is unquestioningly presupposed as status quo, and is not recognized as a particular structuring of reality or way of unconcealment belonging in the concealing-unconcealing of being. Accordingly, conveying both the meaning of "enclosed" as well as "being closed off from," the cybernetic occlusion implies that while we are "enclosed" in the destining of cybernetics, we are concurrently "closed off from" perceiving cybernetics as a specific ontological destining. ${ }^{11}$ The reason for this is that insofar as the relation between being and thinking is "defined and steered" by cybernetics, thinking exclusively looks to beings as things to be regulated, but overlooks — and is "closed off" from noticing — that it thereby already

\footnotetext{
${ }^{9}$ In literature on Heidegger, such unidirectionality is sometimes referred to as "onto-centrism" (see Blok 2016: 459).

${ }^{10}$ This is or course not to say that a tree no longer appears as impressive, beautiful, important etc., but rather means that such experience of beauty is inescapably bound up with the threat of global warming, thereby potentially inciting us to regulate the preservation or multiplication of trees.

${ }^{11}$ In his questioning of technology (see note 7), Heidegger articulates this as the "Danger of Technology" (1977: 27). For a discussion of this danger in relation to the Anthropocene, see Zwier and Blok 2017.
} 
enacts a relation between being and thinking. Due to this occlusion, Heidegger associates cybernetics with the "oblivion of being" (Heidegger 1998b: 259).

In brief then, enclosure, unidirectionality, and occlusion surface as three points of reference that orient Heidegger's ontological interpretation of cybernetics.

\section{Cybernetics and the Anthropocene}

Although the Anthropocene accords to Heidegger's first reference point inasmuch as it offers a concrete experience of our being "enclosed" in cybernetics, it discords with the other two points concerning unidirectionality and occlusion. We therefore propose that the Anthropocene does not imply the ontological forgetfulness that Heidegger articulates as the oblivion of being. Rather, we will argue that the Earth in the Anthropocene engenders a reorientation of Heidegger's interpretation, implying that instead of its oblivion, the Earth can be said to offer a concrete experience of the concealing-unconcealing of being.

To develop this claim, we confront the unidirectionality of cybernetics with the previously discussed twofold Earth ("The Anthropocene and the Intrusion of Asymmetry" section). When asked how the Earth relates to cybernetics, part of the answer is that it appears "enclosed" in the cybernetic "hegemonic domain". As noted previously, this concerns the Earth as the symmetric oikos where things (e.g., coffee, empty fuel tanks, or the earth-system as such) are inescapably encountered in light of global warming and thus according to a collective measure of technological regulation (see "The Anthropocene as Cybernetic Phenomenon" section).

That, however, is only half the answer. The Earth in the Anthropocene is not only a being that is encountered according to a cybernetic relationality, but conjointly appears as the stage upon which the "hegemonic domain" of cybernetics concretely unfolds. This is to say that the Earth is conditioned by cybernetics insofar as it appears as a symmetric oikos that must be regulated, yet itself conversely conditions cybernetics insofar as our regulative encounter with things takes place on Earth as the oikos that 'houses' this encounter. As a first step, therefore, we can say that besides offering a concrete experience of our cybernetic enclosure ("The Anthropocene as Cybernetic Phenomenon" section), the Anthropocene further engenders a peculiar and literal concretion, i.e., a 'growing together' of cybernetics and the Earth.

Be that as it may, the mentioned con-cretion of cybernetics and the Earth remains trivial unless its ontological relevance can be brought out. In conditioning cybernetics by housing its "hegemonic domain," the ontic Earth becomes ontologically relevant inasmuch as it engenders a reorientation of Heidegger's unidirectional consideration of cybernetics. If cybernetics concerns an ontological relation between being and thinking, this relation is enacted by human existence inasmuch as it included in an ontological relationality ("The Anthropocene as Cybernetic Phenomenon" section). Human existence thus appears as a necessary condition for cybernetics. If, in turn, human existence requires an earthly oikos for its wherewithal, then by implication, the Earth surfaces as necessary condition for cybernetics (see Blok 2016). This outwardly trite observation is rendered pertinent by the Anthropocene, because 
the harrowing experience of the intrusion of the asymmetric Earth ("The Anthropocene and the Intrusion of Asymmetry" section) revokes our liberty of taking this condition for granted, and of ignoring how our cybernetic, symmetric oikos itself rests upon a transient Earthly support. If we thoughtfully pursue this experience, we can say that on the one hand, the Earth sustains the oikos upon which human existence can (with Heidegger: obliviously) enact a cybernetic, symmetric relation between being and thinking. On the other hand, in the Anthropocene, the intrusion of the asymmetric Earth renders explicit how the support that sustains this symmetric oikos is not at all unconditional. Instead, it is itself Earth-conditioned by way of a relatively stable exception to a deeply unstable and temperamental rule, where the short-lived chapter featuring humanity as protagonist is experienced to belong to the vast, turbulent, deep timely drama of volatile geo-dynamics that make up what D.T. Ansted once called "the great stone book" of the Earth (1863; see Szerzynski 2012). No longer just the tale of abstract geological science, today, the Earth's asymmetry becomes distressingly tangible by the experience of global warming, foreboding that the brief anthropic chapter in this great stone book is approaching its final readable pages, since the Earth appears on the verge of withdrawing support for the transient, symmetric oikos that we inhabit. Three things follow from this diagnosis.

First, the concretion of cybernetics and the Earth occasions a reorientation of Heidegger's unidirectional interpretation of the relation between the ontic and the ontological, since the Earth now attains a peculiar status. While the Earth as symmetric oikos concurs with Heidegger's interpretation, this oikos itself appears only a minor moment in a major history of the Earth. As indicated, through the experience of the Anthropocene and the asymmetric Earth, today, the Earth appears in a novel way ${ }^{12}$ that is incompatible with Heidegger's unidirectional consideration of cybernetics. Since the being called the Earth is the condition of possibility for the oikos housing human existence, and since this oikos accordingly is the condition of possibility for ontological cybernetics inasmuch as it conditions the cybernetic relation between being and thinking, we can say that rather than being unidirectionally encountered as a being that merely accords to the ontological structuring of cybernetics, the Earth itself emerges as cybernetics' ontic-ontological condition of possibility (see Zwier and Blok 2017; Blok 2016; Blok 2017).

Secondly, and further pursuing an interpretation of the first point, the concretion of cybernetics and the Earth suggests that cybernetics in the Anthropocene cannot be identified with the oblivion of concealing-unconcealing being. In contradistinction to Heidegger's idea that the cybernetic "occlusion" and therewith

\footnotetext{
12 As noted in "The Anthropocene and the Intrusion of Asymmetry" section, objective sciences such as geology and earth-system science have of course long since known about the fact of the asymmetric Earth (e.g., its being much older than human civilisation, more inhospitable than appears at first glance, etc.). However, whereas their propositions concern the Earth or earth-system as scientific object (and thus already unquestioningly enact a theorizing relation between being and thinking, see "The Anthropocene as Cybernetic Phenomenon" section), the experience of the Anthropocene wrests this knowledge from the objective, scientific domain. Phenomenologically speaking, the asymmetry of the Earth no longer merely concerns the ontic domain of a being called the Earth, but comes to pertain to the ontological, cybernetic relation between being and thinking as enacted in our contemporary encounter with the Earth and earthly beings.
} 
associated "oblivion of being" can never be "disjointed" by occurrences at the ontic level ("Heidegger: Cybernetics and Oblivion" section), the twofold Earth of the Anthropocene in fact disjoints this occlusion. Rather than being fully enclosed in the collective measure of cybernetics, the ontic Earth qua symmetric oikos emerges (with Heidegger: is unconcealed) as condition and support for ontological cybernetics, whilst concurrently withdrawing from it (with Heidegger: concealing) inasmuch as the Earth is also alarmingly experienced to remain asymmetric to our cybernetic, symmetric oikos. In other words, although the Anthropocene engenders a concrete experience of our "enclosure" in cybernetics, this does not necessarily entail that we are "closed off" and oblivious to cybernetics as a destining. Instead, the peculiar con-cretion of cybernetics and the Earth in the Anthropocene offers an experience of how the symmetric, cybernetic structuring of reality in which we are inescapably included itself concerns $a$ way of "unconcealment," a way that is itself brought underway via a being named the Earth. This being is thereby not fully "enclosed" in the collective measure of symmetric cybernetics, but conceals itself inasmuch as it remains asymmetric to its unconcealed, briefly inhabitable oikos. In light of the abovementioned peculiar ontic-ontological status of the Earth, it must be stressed that such concealment does not merely pertain to a being that partly withdraws itself (like the dark side of the moon), but pertains to a being that conceals itself in conditioning the very possibility of concealment-unconcealment. As such, we can say that rather than oblivion, the ontic-ontological Earth of the Anthropocene fosters a concrete experience of the concealing-unconcealing of being.

Thirdly, the concretion of cybernetics and the Earth suggests that technology is more ontologically ambivalent and relevant than Heidegger allows for when he says that "scientific-technical planning and making" is always already included in the "most expansive feedback-loop" of cybernetics and can never "disjoint" its occlusion (Heidegger 1983: 145-146; see "Heidegger: Cybernetics and Oblivion" section). To elucidate this point, we note how the abovementioned experience of concealing-unconcealing being is deeply entangled with our technological activity. On the one hand, this experience is technologically mediated inasmuch as it is only through technologies like satellites and computers that we can encounter the Earth as warming globe and experience the associated intrusion of asymmetry (see Ihde 2016: 77-88; Zwier and Blok 2017). On the other hand, the experience of asymmetry emerges in concert with the necessity of responding to its intrusion, and countering it by technologically regulating our Earthly habitat. Now, while such technological regulation clearly adheres to the collective measure, i.e., the symmetry of cybernetics, it is significant that it consists in a counter-measure to something disturbingly asymmetric. And as a counter-measure, our "scientific-technical planning and making" is not only included in the "most expansive feedback-loop" of cybernetics governing our symmetric oikos, but explicitly involves a responsivity to what remains excluded, i.e., asymmetric to this oikos and the cybernetic "hegemonic domain" that it supports. This is to say that although technology appears "enclosed" in cybernetics, it is not necessarily ontologically "closed off" and oblivious. Rather, it involves a responsivity to what remains asymmetric to the collective measure, i.e., the symmetry to which technology adheres. In short, in light of the anthropocenic 
concretion of cybernetics and the Earth, technology comes under consideration as both symmetrically enclosed and as opening towards asymmetry.

Before turning to the question that follows from this, namely how we might understand this responsivity and technological opening towards asymmetry, we first summarize the above. In the Anthropocene, the Earth appears as ontic-ontological condition of possibility for ontological cybernetics. This concretion of cybernetics and the Earth implies that the Earth is not merely a being that is encountered from within a cybernetic relationality, since this only applies to the Earth qua oikos governed by cybernetic symmetry, but not to the Earth that withdraws from cybernetics in the sense of remaining asymmetric to it. Since the Anthropocene heralds the intrusion of such asymmetry, the Earth now offers a concrete experience of the concealing-unconcealing of being. Finally, given how this indication is deeply entangled with our technological activity, technology appears less enclosed, closed off, and ontologically oblivious than Heidegger's interpretation of cybernetics has it. Rather than hermetically enclosed in the collective measure of symmetric cybernetics, technology qua counter-measure becomes responsive and therefore open to what remains asymmetric to it.

Now, while it is clear that an engagement with Heidegger's thought on phenomenology and cybernetics gives rise to the idea of technology and asymmetry, its further investigation must part ways with Heidegger. The reason for this is that Heidegger neither considers the above elucidated ontic-ontological Earth nor the technological opening towards asymmetry that follows from it. ${ }^{13}$ Whilst Heidegger solely understands technological activity as included in cybernetics and thus as exclusively symmetric, the Anthropocene compels us to question technology beyond its cybernetic enclosure.

In what follows, we therefore part ways with Heidegger to encounter in Georges Bataille a thinker whose consideration of technology flanks Heidegger's, yet diverges from it inasmuch as it articulates an asymmetry on the part of technology, thus allowing us to come to terms with technology in relation to both the symmetric and asymmetric Earth. ${ }^{14}$

\footnotetext{
${ }^{13}$ It may strike the reader that an explicit confrontation with Heidegger's thematization of Earth remains absent here. On the one hand, this absence may be explained by the fact that although Heidegger speaks of the Earth on various occasions, it never comes under consideration in its Anthropocenic manifestation as the ontic-ontological condition for the destining of cybernetics-which is the central theme of this paper. On the other hand, we should note that the arguments presented here build on a more explicit analysis of Heidegger and the Earth as presented in Blok (2016). For a good discussion of Heidegger and the Earth, see Haar (1993).

${ }^{14}$ In what follows, we will interpret Bataille in light of the previous discussion of Heidegger, thereby aligning their often diverging vocabularies by casting them in the same mould. The idea behind such an alignment is that it allows us to address the issue of technology and asymmetry in relation to both Heidegger's thought and the phenomenon of the Anthropocene. For a more generally oriented confrontation between Heidegger and Bataille, see Comay (1990), Lee Jr. (2007).
} 


\section{Bataille: Asymmetry and Technology}

Although Bataille does not systematically engage with the question of technology as such, the way in which it figures in his diagnosis of human existence is instructive for understanding the implications of the aforementioned technological rapport with the Earth, as well as the associated opening towards asymmetry. In what follows, we will see how contrary to Heidegger, Bataille allows for a consideration of an ontological asymmetry that is engendered by technology itself.

\section{Aversive Technology}

To see this, we begin by noting how Bataille takes technology to characterize the way in which human existence inhabits the Earth. This habitation is typified by a technically induced aversion from that which constitutes humanity in the first place, namely nature. Nature is understood in terms of what Bataille calls "the general economy" (1991), which is principally characterized by abundance, meaning that the energetic abundance of the sun constitutes natural organisms and propels life on the surface of the Earth. Bataille takes it as "a basic fact" that because the influx of solar energy is unremitting, natural organisms receive more energy than strictly required for maintaining life, resulting in excess energy (Bataille 1991: 21). He articulates this in terms of "pressure" (1991: 29-36), the first effect of which is expansion, as this reduces pressure via spatial distribution. If otherwise unhindered, growth eventually runs up against spatial limits, and since the sun remains impartial to such limits and continues to relentlessly bestow its energizing gift, surplus energy can eventually no longer be incorporated via growth, but must be dissipated or wasted. In nature, therefore, "the impossibility of continuing growth makes way for squander" (1991: 29) via "the production of increasingly burdensome forms of life" (1991: 33). Where, for instance, plants make relatively efficient use of the sun's gift for growth, ${ }^{15}$ higher organisms eat plants and other animals without growing to the same extent, thus making self-preservation and growth a more 'burdensome' affair. Additionally, the extravagant, intricate, and painstakingly extensive sexual behaviours of higher organisms imply a relatively inefficient way of procreation: "the mammalian organism is a gulf that swallows vast quantities of energy" (Bataille 1986: 60; see Stoekl 2007b: 255). Bataille does thereby not deny that natural life occasionally faces shortages and accordingly engages in a struggle for survival, but he interprets such a struggle as constituted by, and partaking in the general movement of energy that is characterized by abundance and ultimately by squander. For example, a hungry lion faces a shortage of food, but its hunting and eating of a zebra (which itself 'swallows vast quantities of energy' by inefficiently feeding on grass) partakes in the carnivorous squander of the abundant energy that constitutes the grass, the zebra, and the lion. Were we to align Bataille's ideas with the previous

\footnotetext{
15 Although relatively efficient (in comparison to higher organisms), plants also involve their own 'burdensome' ways, e.g. the fruitless sexuality of flowering plants (see Wendlin 2007: 39).
} 
discussion of Heidegger, phenomenology, and cybernetics, we might say that while the ontic level of individually constituted beings may face scarcity and struggle, the ontological constitution as such is characterized by the abundance of the general economy. $^{16}$

Now, for Bataille, natural organisms are fully immersed in nature "like water in water" (1989a: 19), implying that they blindly partake in both the struggle for survival and implicated squander of energy. Conversely, he interprets the human being as the natural organism that, by way of technology, averts from nature and from the general economy that constitutes it, ${ }^{17}$ meaning that humans enter into a specific, namely forgetful relation with the energy that (ontologically) constitutes them.

Bataille refers to this forgetful relation as the "restricted economy" (1991: 19-41). This means that human existence restricts its dealings to individual beings and goods, thereby forgetting about the abundance of the general economy that ontologically constitutes such beings. Analogous to our colloquial understanding of economy, the restricted economy is characterized by scarcity, necessity, and work. In averting from nature and the general economy, human existence abhors the re-submergence in nature called death (Bataille 2007: 73, 79-86), and the corresponding strife for selfmaintenance evidently needs resources that do not come naturally, but are considered as scarce goods, thus demanding productive work to compensate for this deficit. One may think of agriculture as an example, where the constitutive abundance of the sun is forgotten inasmuch as its energy is 'restrictively' encountered as a scarce good that needs to be put to work in order to secure a good harvest, the crops of which are similarly considered as scarce goods to be traded in an economy where their value derives from supply and demand (see Zwier et al. 2015: 360-362).

Yet although human existence in the restricted economy seems similar to a hungry lion inasmuch as both strive towards self-maintenance, Bataille stresses that:

The purpose of a plow is alien to the reality that constitutes it; and (...) the same is true of a grain of wheat or a calf. (Bataille 1989a: 41).

This is to say that whereas a lion is immersed in the "reality that constitutes it" (like water in water), technology (e.g., the plow) induces human existence to engage in an 'alienated', i.e., averted relation to this reality. This differs from the lion's natural immersion in two significant ways, both of which turn out to be relevant to the Anthropocene.

First, encountering things according to the restricted economy involves thinking, namely "the consciousness of a necessity, or an indigence" (Bataille 1991: 23),

\footnotetext{
16 Bataille of course does not put any of this in terms of 'ontic' and 'ontological' or in relation to Heidegger's ontological difference. However, we maintain that Bataille's differentiation of constituted beings and their constitution as such (the general economy) can-to a certain extent as we shall see-be aligned with Heidegger's differentiation of being and beings. As will be argued, doing so is significant for understanding technology and asymmetry in the Anthropocene.

17 With respect to this aversion, Bataille follows a Hegalian trajectory: "Man is the animal that negates nature: he negates it through labor, which destroys it and changes it into an artificial world; he negates it in the case of life-creating activity; he negates it in the case of death." (2007: 61; see 52). For an elaborate discussion of Bataille's Hegel interpretation, see Gemerchak (2003). For a discussion of Hegelian negation, the Anthropocene, and the Earth, see Zwart (2017).
} 
where we think that work is needed to meet our necessities. Aligning this with our discussion of phenomenology ("The Anthropocene as Cybernetic Phenomenon" section), we can interpret the restricted economy as a relation between being and thinking, where being (with Bataille: the constitutive "reality" in the above citation) is thought of in terms of beings that are scarce, needed, and thus require work. This is relevant to our discussion of the Anthropocene, because this 'restricted' relation between being and thinking resonates with Heidegger's interpretation of cybernetics, given how both articulate an encounter with beings that is principally characterized by regulative, purposeful work. We can therefore say that due to a technologically induced aversion, humanity enters into the restricted economy and thus comes to inhabit the Earth as symmetric oikos, in which being and thinking become symmetric inasmuch as their relation is structured according to the collective measure, i.e., symmetry of scarcity, necessity, and (regulative) work.

Secondly, for Bataille, the aversion that gives rise to this symmetric, 'restricted' encounter with things is never definitive. Instead, human existence in the restricted economy remains exposed to what it averts from in two ways, which we will discuss as abundance and waste. Our hypothesis is that this twofold exposure is relevant for questioning technology in the Anthropocene, because it implies that the technologically induced aversion and associated forgetful habitation of the Earth as oikos in which being and thinking become symmetric, comes to be reminded of that what constitutes it whilst remaining asymmetric to it. ${ }^{18}$ Understanding technology in this way allows for addressing the question raised at the end of the "Phenomenon and Asymmetry" section, thus coming to terms with technology's opening towards asymmetry.

\section{Aversion and Abundance}

Abundance implies that the symmetric, restricted way of encountering beings is not definitive, because the technologically induced aversion and associated habitation of a symmetric oikos does not disconnect this oikos from the abundance that constitutes it. Although forgetful of the constitutive abundance of the general economy, human existence remains subjected to its ceaseless influx of energy. Bataille's twofold diagnosis of his own time is instructive here: first of all, in considering energy as a scarce good of which more is always needed, modern, industrial humanity accumulates and produces massive amounts of energy via large-scale extraction of fossil fuels and nuclear power (see Stoekl 2007a: 40-41). Secondly, forgetfulness of the general economy gives rise to equating a healthy economy with a growing economy, which celebrates employment whilst scowling at wastefulness. ${ }^{19}$ Bataille sees the pairing of the two as a recipe for

\footnotetext{
18 This is specific to humanity: immersed in nature like water in water, a lion neither forgets nor is reminded of the general economy.

19 Elaborately analyzing Bataille's (cultural) diagnosis of how this entrenchment and associated forgetfulness of the general economy came about-in which the rise of Protestantism, capitalism, and industrialism are central-is beyond the scope of this paper (see Bataille 1991: particularly 115-141).
} 
catastrophe: because the large influx of energy is not allowed to be wasted, the human oikos can only expand under the pressure of abundance (which is welcomed as economic growth). However, when growth eventually runs out of space, pressure builds up, and as with any limited system that is subjected to increasing pressure, it ultimately explodes. Writing in the aftermath of two world wars which he understands as "the greatest orgies of wealth that history has recorded" (1991: 37), Bataille envisages - with Argus' eyes - the eruption of another war as the explosive and catastrophic outcome of (or rather outlet for) uncontainable pressure. As with other constituents of the general economy, "the impossibility of continuing growth makes way for squander" (1991: 29), which in the case of forgetful human existence takes the catastrophic form of war. In this way, the restricted way of encountering things in terms of scarcity, necessity, and (regulative) work-i.e., habitation of a symmetric oikos-is not definitive and must ultimately come to terms with what remains asymmetric to it, as it postpones but cannot avoid the consequences of its abundance-driven constitution.

Still, because of their technologically induced aversion, humans are unlike other natural organisms, and do not blindly, but forgetfully partake in the growth and squander engendered by the abundance of the general economy. On the one hand, in light of its recipe for catastrophe, Bataille considers such forgetfulness "a failure of humanity" (2007: 15; see 1991: 21). On the other hand, because human existence is not blindly preordained to this failure, Bataille envisages an alternative.

In exploring this alternative, Bataille investigates cultural history for ways of "exhausting the surplus without war" (2007: 428), and finds a pressure exhaust in the ritual of potlatch, where the indigenous people in the American northwest wasted surplus energy by way of the destruction of accumulated and produced resources, for instance by killing one's own slaves, wrecking one's canoes, up to setting one's own village on fire (Bataille 1991: 67-68). Other examples include pyramids as a rather inefficient burial method (1991: 119), Lamaist monks who avoided activity in contemplative life, thus dissipating the surplus generated by Tibetan workers (1991: 93-110), jewels, works of art (Bataille 1989b; see Wendlin 2007: 39), and eroticism (Bataille 1986; 2007). All of these indicate a different relation to energy: rather than considering it a scarce good to be put to work, they acknowledge rather than forget its constitutive abundance, accordingly attesting to how "it is not necessity but its contrary, "luxury" that presents living matter and mankind with their fundamental problems" (Bataille 1991: 12).

While more must and will be said about such a way of confronting abundance and the Anthropocene, we first recapitulate how technology figures in all of this. On the one hand, technology induces an aversion from nature and the general economy, thus facilitating habitation of an oikos that is characterized by a symmetric relation between being and thinking, meaning that beings are encountered in terms of the restricted economy of scarcity, necessity, and (regulative) work. As aversive, technology engenders forgetfulness of the constitutive abundance of the general economy, leading the human symmetric oikos to expand. On the other hand, inasmuch as this forgetful aversion remains exposed to the general economy, technology also gives rise to a specific (catastrophic or other) confrontation with the abundance that remains asymmetric to it. 

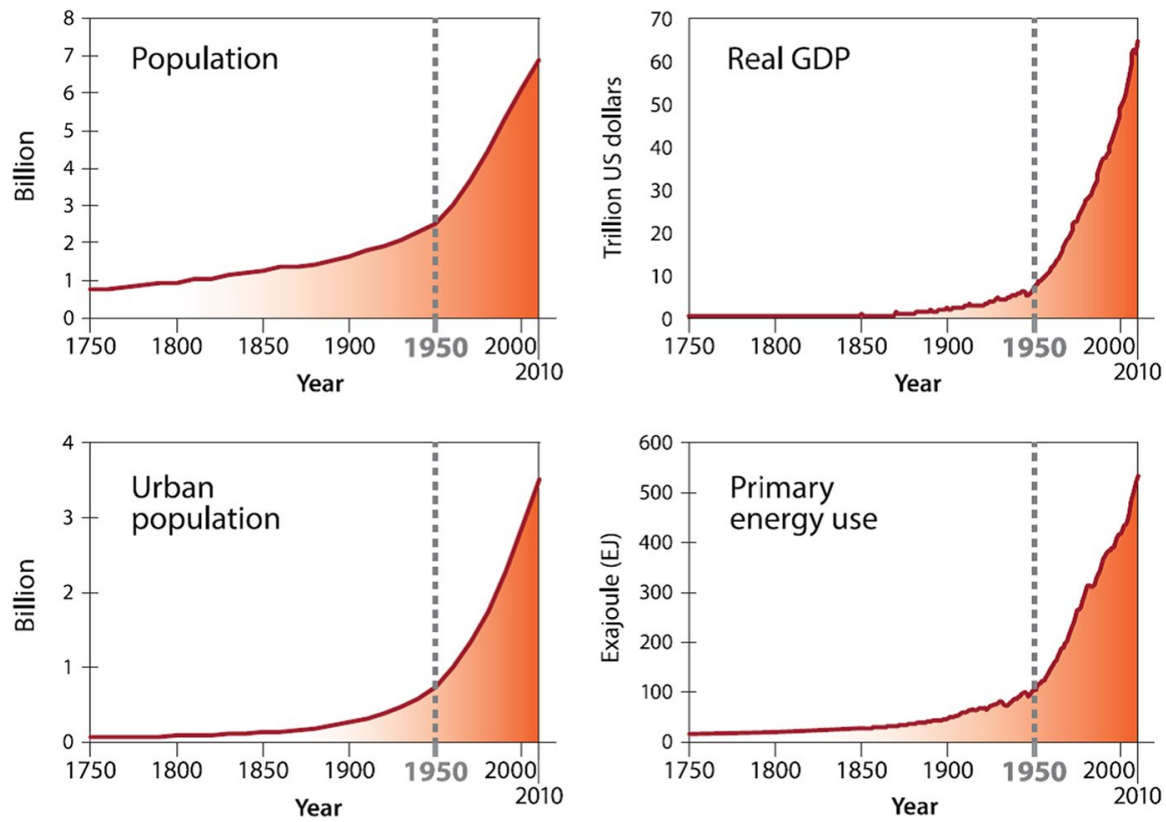

Fig. 1 The Great Accelleration (image source: Steffen et al. 2015: 84)

Translating all of this to the Anthropocene, we can see the Anthropocene as a concrete manifestation of the human symmetric oikos being exposed to the abundance of the general economy. If abundance engenders pressure which in turn effects expansion, the Anthropocene can be seen as its result. Whatever its exact starting point, it is clear that the Anthropocene involves an enormous increase of human beings on the planet since that point, paired with an equally tremendous accumulation, production, and transformation of natural and energetic resources. The following graphs depicting "the great acceleration" (Fig. 1) express this better than anything:

In light of this expansion, we can see the Anthropocene as an effect of humanity's (technologically induced) aversion from the general economy and associated entrenchment in the restricted economy. If such entrenchment entails forgetfulness of the constitutive abundance of the general economy, and if such forgetfulness entails that the human, symmetric oikos must expand (given how energy appears a scarce good to be accumulated and not wasted), then the Anthropocene has this oikos expanding to a planetary scale, thereby rendering its anthropic inhabitant the dominant geological factor.

With Bataille, therefore, we can add an economic dimension to our previous discussion of cybernetics. We have seen how the Anthropocene offers a concretisation of our inclusion in a cybernetic, symmetric relationality ("The Anthropocene as Cybernetic Phenomenon" section). We can now interpret this relationality to belong to a technologically induced aversion from the general economy, by which humanity comes to inhabit the Earth as the oikos in which being and thinking become 
symmetric. As with Heidegger's cybernetics, this symmetrical way of encountering things is ontologically forgetful ("Phenomenon and Asymmetry" section). Unlike Heidegger, however, it is not wholly "closed off," since the aversion that engenders such forgetfulness is not definitive, as it postpones but cannot avoid the consequences of its abundance-driven constitution. What follows is that the forgetful, symmetric way of encountering things and goods eventually comes to be reminded of its forgetfulness and must therefore, whether catastrophically or other, come to terms with the constitutive abundance that remains asymmetric to it.

Be that as it may, in the Anthropocene, this reminder of forgetfulness occurs in another significant way as well. We therefore turn to waste as the second way by which human existence remains exposed to what is averts from.

\section{Unceasing Departure: Aversion and Waste}

As noted, human existence averts from nature, meaning that instead of being immersed 'like water in water,' humans depart from nature to enter into a specific, forgetful relation with it. This aversion is not definitively forgetful, because human existence remains exposed to the nature from which it averts "and from which man does not cease to have departed" (Bataille 2007: 62).

For Bataille, this unceasing departure from nature is evidenced by "the horror of nature, which was the first movement of the process (...) that established humanity" (2007: 77). This horror becomes most eminently manifest in the form of our own abhorred natural waste: decaying corpses, vomit, faeces, urine, menstrual blood, the odour of sweat, etc. (Bataille 2007: 61-88). Whilst from the perspective of nature, there is nothing extraordinary about these dejecta (faeces are simply a resource for the continuation of organic life, as are rotting corpses), ${ }^{20}$ they invoke disgust and abhorrence in us, because they serve as a horrific reminder of a nature with which we no longer coincide inasmuch as we have averted from it.

If technology induces this aversion or departure from nature, it also serves to contain the horrors associated with not having ceased this depart from it. Think of sewer-systems, toilets, tampons, deodorant, cemeteries, etc. Such containment is rather successful, particularly in highly technological societies (see Scanlan 2005), but is never flawless and definitive, e.g., when we occasionally encounter an unflushed, rancid toilet, or are overwhelmed by the fetid stench of a passing garbage truck. In those cases, when technological containment momentarily hampers and we are confronted with our natural waste, we usually shudder, flush the toilet, avert ourselves once more, and go about our business. Technology then both induces the departure from nature, and serves to contain its consequent horrors, thus affording human existence to mostly forget about its unceasing departure.

What does this have to do with the Anthropocene? In the Anthropocene, we are confronted with the waste that technology itself dejects in its aversion from nature and the general economy. We have seen how it is due to this aversion that the Earth

${ }^{20}$ In this regard, Bataille also notes how "the [human] loathing of decay $(\ldots)$ is not shared by animals" (2007: 79). 
Fig. 2 Amospheric $\mathrm{CO}_{2}$ at Mauna Loa Observatory (image source: https://www.esrl.noaa. gov/gmd/ccgg/trends/full.html)

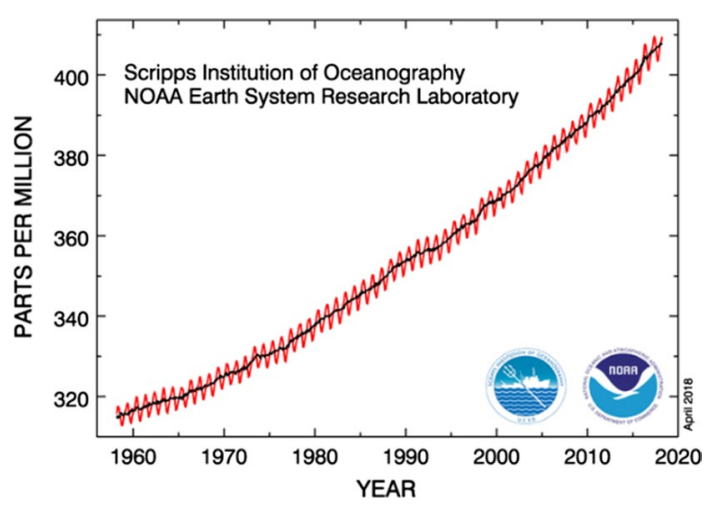

becomes inhabited as symmetric oikos, which the Anthropocene concretely demonstrates by the expansion of the human oikos via the large-scale exploitation of fossil fuels. Indeed, it is only because of the (symmetric and infernal) coupling of humans and fossil fuels that the Anthropos becomes the dominant geo-force ("The Anthropocene and the Intrusion of Asymmetry" section). Now, the waste of this combustive exploitation goes under the name of $\mathrm{CO}_{2} \cdot{ }^{21}$ We propose that in the Anthropocene, it acquires a status once occupied by natural dejecta.

In order to see this, we must engage in a phenomenological exercise and investigate the experience of $\mathrm{CO}_{2}$. The first thing to note is that we neither directly see $\mathrm{CO}_{2}$, nor experience the horrific disgust as when confronted with vomit, faeces, or rotting corpses. We only have a remote experience of $\mathrm{CO}_{2}-$ as data rendered in graphs. Be that as it may, in the Anthropocene, $\mathrm{CO}_{2}$ encroaches and becomes less and less remote. Consider the following graph on "Atmospheric $\mathrm{CO}_{2}$ " (Fig. 2):

If we let this graph sink in, it becomes something other than just another graph depicting abstract and remote scientific data. Instead, put phenomenologically, it quite literally sinks in, namely into the very way in which we encounter the world, as it becomes concrete in the sense of growing together with everything we see, as if etched in our peripheral vision. The line above $400 \mathrm{ppm}$ attaches itself to the trails of airplanes we see when looking at the sky, to the freight train carrying a batch of new cars to the harbour, to the warning light signalling an empty fuel tank, to the adverts for exotic holiday destinations, to the trees in the garden, the powerlines across the field, etc.

When pausing over what this (concrete, sunk in) graph actually says, one feels queasy to say the least-one dreads it and feels gutted. Why? Because in engendering global warming, $\mathrm{CO}_{2}$ stands as a stark reminder of how the symmetric, fossilfueled, and now planetary oikos that we inhabit and usually take for granted, remains encompassed by the asymmetric Earth that constitutes it and momentarily grants it

\footnotetext{
${ }^{21} \mathrm{CO}_{2}$ is obviously not the only form of waste exhausted by the anthropic geo-force, but it is arguably the most significant, as evidenced by the fact that the impact of other forms of waste are often expressed in $\mathrm{CO}_{2}$-equivalence $\left(\mathrm{CO}_{2}\right.$-e).
} 
stable support. And through the fumes of $\mathrm{CO}_{2}$ that thicken the air, we behold the intrusion of the asymmetric Earth, the associated withdrawal of stable support, and catch a glimpse of how this stable support is but an exception to the rule of a deeply unstable and unsettled Earth ("The Anthropocene and the Intrusion of Asymmetry" section).

It is for this reason that in the Anthropocene, $\mathrm{CO}_{2}$ can be ascribed similar status as natural dejecta. As with natural dejecta, there is nothing extraordinary about $\mathrm{CO}_{2}$ from the perspective of the Earth as such, since it is but one of many parameters of the cybernetic earth-system, including natural life for which it is a resource. Yet for human existence, it emerges as a horrific souvenir of unceasing departure. Where natural dejecta remind of a constitutive nature from which human existence does not cease to depart, $\mathrm{CO}_{2}$ horrifically reminds of how our oikos on the symmetric Earth does not cease to depart from the Earth that constitutes it and remains asymmetric to it.

The response to the confrontation with the horrific waste of $\mathrm{CO}_{2}$ follows along this parallel, as it consists in once more averting oneself by way of technology. In the same way that technologies like toilets and cemeteries contain natural dejecta, we can buy carbon compensation when booking a flight, drink ecologically certified coffee from " $100 \%$ biodegradable" cups, and put up solar panels to contain $\mathrm{CO}_{2}$. In contrast to natural waste however, the Anthropocene testifies to a clogged toilet, no longer able to contain the flurry of waste. This is to say that technologically containing and thus averting from the waste called $\mathrm{CO}_{2}$ becomes increasingly impossible as the fumes linger. One of the dreaded lessons that earth-system science teaches is that $\mathrm{CO}_{2}$ is not simply present or absent, and cannot simply be flushed, since it figures as a parameter in all kinds of intricate cybernetic feedback-loops of the earth-system, including positive loops. As a simple example, if $\mathrm{CO}_{2}$ engenders global warming and effects the melting of the arctic, less sunlight is reflected, thus fomenting further warming, more rapid melting, even less reflection, etc. (ad nauseam indeed). Hence, whereas with respect to the horrific reminder of natural dejecta, technological containment affords human existence to mostly forget about its departure from nature and go about its business, the dejecta of $\mathrm{CO}_{2}$ - the very waste-trail of this technologically fuelled departure - cannot be contained in this way, and therefore do not allow for forgetting about our unceasing departure from the asymmetric Earth.

What follows, in sum, is that while technology induces an aversion that proceeds towards symmetry and habitation of the Earth as a symmetric oikos, the waste-trail of $\mathrm{CO}_{2}$ engendered by this technological aversion compels - through the fumes-an experience of how human existence does not cease to avert from that from which remains asymmetric to it.

\section{Conclusion: Asymmetric Exposure}

Compounding the previous sections, we can interpret the Anthropocene as the time in which we are inescapably reminded of asymmetry, since the Anthropocene concretely shows that the technological, restricted symmetry is not definitive, but is instead confronted with what remains asymmetric to it. On the one 
hand, the Anthropocene appears as an effect of our technologically induced, forgetful diversion from the abundance of the general economy, where continued exposure to this constitutive abundance entails that under pressure, our symmetric oikos expands to planetary dimensions, and continues to do so, even in (twi) light of horrific $\mathrm{CO}_{2}$. We can take this as another indication of the pressurizing general economy, i.e., the asymmetric constitutive abundance from which symmetric human existence continues to divert, with no foreseeable end in sight. On the other hand, the very waste-trail exhausted by this technological diversion binds our eyes to a foreseeable end, as it compels - through the fumes-attention to the intrusion of the asymmetric Earth. The technological waste of $\mathrm{CO}_{2}$ thereby comes to serve as a horrific reminder of how our symmetric oikos does not cease to depart from the asymmetric Earth, whilst alarmingly signalling how it stands on the verge of in fact ceasing from this departure and collapsing back into its earthly bedrock.

From this confrontation between Heidegger and Bataille in the Anthropocene, we conclude that technology in the Anthropocene is ontologically forgetful, but not wholly oblivious. Retracing our steps, we saw Heidegger associating technological activity with the oblivion of being, since he considers it to be both "enclosed" and "closed off" from the ontological destining of cybernetics and its collective measure or symmetry of regulation ("Phenomenon and Asymmetry" section). We refused Heidegger's interpretation by arguing that the ontic-ontological Earth offers an experience of the concealing-unconcealing of being. Furthermore, since this experience is deeply entangled with technology, we intimated that technology involves an opening towards asymmetry, because its regulative symmetry appears as a countermeasure to the intrusion of the asymmetric Earth. At this stage, it should be stressed that such an opening towards asymmetry does not merely imply an awareness of something that technology cannot (yet) master and bring under its collective measure. Rather, due to its rapport with the ontic-ontological Earth as that what conditions our technological encounter with things, the stated opening towards asymmetry allows for an experience of our technological, regulative encounters as a mode of encounter that is itself 'meted out' by the process of concealing-unconcealing being. This then illustrates technology's twofold ontological relevance insofar as it relates both to the (unconcealed) Earth understood as the symmetric oikos that conditions cybernetics which encloses technological activity, whilst concurrently relating to the Earth that withdraws (or conceals itself) from this enclosure by remaining asymmetric to it.

Bataille helps to further understand this technological opening towards asymmetry, since he articulates how technology induces a diversion that proceeds towards symmetry, but does not, due to abundance and waste, definitely accomplish a symmetric enclosure. On the one hand then, technology is forgetful, given how it induces human existence to divert from nature and the abundance of the general economy that constitutes it, engendering a forgetful entrenchment in the restricted economy and habitation of the Earth as the oikos in which being and thinking become symmetric. The Anthropocene concretely gives the reckoning of this, as the human oikos expands to planetary dimensions, rendering its forgetful inhabitant the dominant geo-force. Furthermore, inasmuch as it serves to contain the horrific natural dejecta 
that remind human existence of its departure from nature, technology affords forgetfulness of its own diversion.

On the other hand, in the Anthropocene, the uncontainable waste-trail of this technological diversion itself $-\mathrm{CO}_{2}$-emerges as the horrific souvenir that retaliates against forgetfulness. By way of its own dejecta, technology can then be said to come to terms with itself as it awakens a twofold memory, incriminating what technology diverts from (the asymmetric Earth and the general economy), and that it unceasingly does so.

We therefore conclude that the Anthropocene gives rise to a twofold conceptualization of technology according to which technology becomes ontologically significant. First, technology is conceptualized as always already and forgetfully "enclosed" in a symmetric relation between being and thinking. Secondly, technology offers a reminder of how its own symmetric enclosure results from an unceasing diversion from that which remains asymmetric to it. On the one hand, technology diverts from the asymmetric Earth as the ontic-ontological condition for the oikos that supports technology's symmetric enclosure ("Phenomenon and Asymmetry" section). On the other hand, technology diverts from the general economy to which this oikos remains exposed ("Bataille: Asymmetry and Technology" section). This conceptualization is ontologically significant, because in coming to terms with its own forgetful diversion, technology fosters-through the fumes-responsivity to being, i.e., to what always already structures how we symmetrically encounter things, whilst remaining asymmetric to this encounter.

Such a conceptualization of technology is relevant for philosophy of technology in the Anthropocene, particularly in light of how various symptoms of the asymmetric Earth's intrusion (e.g., global warming, atmospheric $\mathrm{CO}_{2}$, im-permafrost etc.) are now being met with technological responses. Examples include initiatives like 'circular bio-based economy' (see Zwier et al. 2015), 'clean energy,' up to 'geoengineering' and the like (see Hamilton 2013). While acknowledging the asymmetry of the Earth, such initiatives are oriented towards symmetry inasmuch as they attempt to keep the asymmetric Earth at bay by (re)introducing runaway earth-system parameters into a regulative feedback loop, thus safeguarding habitability. We maintain that philosophy of technology cannot avoid acknowledging the need for such initiatives. Whereas the role of technology will increasingly consist in symmetric maintenance of our habitat by regulating the fumes exhausted by our technological modus vivendi, it is the vocation of the philosophy of technology to diagnose this modus, to see through the fumes and cultivate the question what today's confrontation between technology and the Earth means for its forgetful yet responsive inhabitants.

Open Access This article is distributed under the terms of the Creative Commons Attribution 4.0 International License (http://creativecommons.org/licenses/by/4.0/), which permits unrestricted use, distribution, and reproduction in any medium, provided you give appropriate credit to the original author(s) and the source, provide a link to the Creative Commons license, and indicate if changes were made. 


\section{References}

Ansted, D. T. (1863). The great stone book of nature. London: Macmillan \& Co.

Baskin, J. (2015). Paradigm dressed as epoch: The ideology of the Anthropocene. Environmental Values, 24, 9-29.

Bataille, G. (1986). Erotism: Death and sensuality (trans: Dalwood, M.). San Francisco: City Lights Books.

Bataille, G. (1989a). Theory of religion (M. Dalwood, Trans.). New York: Zone Books.

Bataille, G. (1989b). The tears of eros (P. Connor, Trans.). San Francisco: City Light Books.

Bataille, G. (1991). The accursed share Vol. I (R. Hurley, Trans.). New York: Zone Books.

Bataille, G. (2007). The accursed share Vol II \& III (R. Hurley, Trans.). New York: Zone Books.

Blok, V. (2016). Thinking the earth: Critical reflections on quentin meillassoux's and heidegger's concept of the earth. Environmental Ethics, 38(4), 441-462.

Blok, V. (2017). Earthing technology. Techné: Research in Philosophy and Technology, 21(2), 127-149.

Clark, N. (2011). Inhuman nature. Sociable life on a dynamic planet. Los Angeles: Sage.

Clark, N., \& Yusoff, K. (2014). Combustion and society: A fire-centred history of energy use. Theory, Culture \& Society, 31(5), 203-226.

Comay, R. (1990). Gifts without presents: Economies of "experience" in Bataille and Heidegger. Yale French Studies, 78, 66-89.

Crutzen, P. J. (2002). Geology of mankind: The anthropocene. Nature, 415, 23.

Crutzen, P. J. (2004). Anti-Gaia. In W. Steffen, et al. (Eds.), Global change and the earth system: A planet under pressure. New York: Springer.

Crutzen, P. J., \& Schwägerl, C. (2011). Living in the Anthropocene: Toward a new global ethos. Yale Environment, 360. http://e360.yale.edu/feature/living_in_the_anthropocene_toward_a_new_globa 1_ethos/2363/. Accessed 20 Oct 2016.

Dumanoski, D. (2009). The end of the long summer: Why we must remake our civilization to survive on a volatile earth. New York: Three Rivers Press.

Fagan, B. (2004). The long summer: How climate changed civilisation. Cambridge: Basic Books.

Gemerchak, C. M. (2003). The sunday of the negative. Reading Bataille reading Hegel. New York: SUNY Press.

Haar, M. (1993). The song of the earth: Heidegger and the grounds of the history of being. Indiana: Indiana University Press.

Hamilton, C. (2013). Earthmasters. Playing god with the climate. New Haven: Yale University Press.

Hamilton, C. (2016). The Anthropocene as rupture. The Anthropocene Review, 3, 93-106. https://doi. org/10.1177/2053019616634741.

Hamilton, C., Bonneuil, C., \& Gemenne, F. (2015). Thinking the Anthropocene. In C. Hamilton, C. Bonneuil, \& F. Gemenne (Eds.), The Anthropocene and the Global Environmental Crisis (pp. 1-13). London: Routledge.

Hayles, K. (1999). How we became posthuman. Virtual bodies in cybernetics, literature, and informatics. Chicago \& London: University of Chicago Press.

Heidegger, M. (1972). On time and being (J. Stambaugh, Trans.). New York: Harper \& Row.

Heidegger, M. (1977). The question concerning technology and other essays (W. Lovitt, Trans.). New York: Harper and Row.

Heidegger, M. (1983). Die Herkunft der Kunst und die Bestimmung des Denkens. In M. Heidegger (Ed.), Denkerfahrungen (pp. 135-149). Frankfurt am Main: Vittorio Klostermann.

Heidegger, M. (1998a). On the essence of truth (J. Sallis, Trans.) In W. NcNeill (Ed.) Pathmarks (pp. 136-154). Cambridge: Cambridge University Press.

Heidegger, M. (1998b). Letter on humanism (F. A. Capuzzi, Trans.) In W. McNeill (Ed.) Pathmarks (pp. 239-276). Cambridge: Cambridge University Press.

Heidegger, M. (1999.) Contributions to philosophy (From Enowning) (P. Emad \& K. Maly, Trans.). Bloomington: Indiana University Press.

Heidegger, M. (2001). Zollikon seminars. Protocols-Conversations-Letters (F. Mayr, Trans.). Evanston, IL: Northwestern University Press.

Heidegger, M. (2004). The phenomenology of religious life (M. Fritsch \& J. A. Gosetti-Ferencei, Trans.). Bloominton: Indiana University Press.

Heidegger, M. (2008). Being and time (J. Macquarrie \& E. Robinson, Trans.). New York: Harper \& Row. 
Heidegger, M., \& Fink, E. (1979). Heraclitus seminar 1966/1967 (C. H. Seibert, Trans.). University of Alabama Press.

Ihde, D. (2016). Husserl's missing technologies. New York: Fordham University Press.

Latour, B. (2017). Facing Gaia: Eight lectures on the new climatic regime. Cambridge: Polity press.

Lee, R. A., Jr. (2007). Politics and the Thing: Excess as the Matter of Politics. In S. Winnubst (Ed.), Reading Bataille now (pp. 240-251). Bloomington and Indianapolis: Indiana University Press.

Lorimer, J. (2016). The anthropo-scene: A guide for the perplexed. Social Studies of Science. https://doi. org/10.1177/0306312716671039.

Lynas, M. (2011). The god species: How the planet can survive the age of humans. London: HarperCollins.

McGuire, B. (2013). Waking the giant: How a changing climate triggers earthquakes, tsunamis, and volcanoes. Oxford: Oxford University Press.

Morton, T. (2013). Hyperobjects. Philosophy and ecology after the end of the world. Minneapolis and London: University of Minnesota Press.

Scanlan, J. (2005). On garbage. London: Reaktion Books.

Steffen, W., Broadgate, W., Deutsch, L., Gaffney, O., \& Ludwig, C. (2015). The trajectory of the Anthropocene: The great acceleration. The Anthropocene Review, 2(1), 81-98.

Steffen, W., Crutzen, P. J., \& McNeill, J. R. (2007). The Anthropocene: Are humans now overwhelming the great forces of fature? Ambio, 36(8), 614-621.

Steffen, W., Grinevald, J., Crutzen, P., \& McNeill, J. (2011a). The Anthropocene: Conceptual and historical perspectives. Philosophical Transactions of the Royal Society A, 369, 842-867.

Steffen, W., Persson, Å., Deutsch, L., Zalasiewicz, J., Williams, M., Richardson, K., et al. (2011b). The Anthropocene: From global change to planetary stewardship. Ambio, 40(7), 739-761. https://doi. org/10.1007/s13280-011-0185-x.

Stengers, I. (2009). In Catastrophic times: Resisting the coming barbarism. (Goffey, A., Trans.). www. openhumanitiespress.org. Accessed 09 Feb 2017.

Stengers, I. (2015). Accepting the reality of Gaia: A fundamental shift? In C. Hamilton, C. Bonneuil, \& F. Gemenne (Eds.), The anthropocene and the global environmental crisis (pp. 134-145). London: Routledge.

Stoek1, A. (2007a). Bataille's peak: Energy, religion, and postsustainability. Minneapolis: University of Minnesota Press.

Stoekl, A. (2007b). Excess and depletion: Bataille's surprisingly ethical model of expenditure. In S. Winnubst (Ed.), Reading Bataille now (pp. 252-282). Bloomington and Indianapolis: Indiana University Press.

Szerszynski, B. (2012). The end of the end of nature: The anthropocene and the fate of the human. Oxford Literary Review, 34(2), 165-184.

Walker, B., \& Salt, D. (2006). Resilience thinking. Sustaining ecosystems and people in a changing world. Washington, DC: Island Press.

Wendlin, A. E. (2007). Sovereign consumption as a species of communist theory. In S. Winnubst (Ed.), Reading Bataille now (pp. 35-53). Bloomington and Indianapolis: Indiana University Press.

Williston, B. (2017). The question concerning geo-engineering. Techné: Research in Philosophy and Technology. https://doi.org/10.5840/techne201772166.

Zalasiewicz, J., Williams, M., Steffen, W., \& Crutzen, P. (2010). The new world of the Anthropocene. Environmental Science and Technology, 44, 2228-2231.

Zwart, H. (2017). From the nadir of negativity towards the cusp of reconciliation. A dialectical (HegelianTeilhardian) assessment of the anthropocenic challenge. Research in Philosophy and Technology. https://doi.org/10.5840/techne20176565.

Zwier, J., \& Blok, V. (2017). Saving earth: Encountering heidegger's philosophy of technology in the anthropocene. Techné: Research in Philosophy and Technology. https://doi.org/10.5840/techne2017 72167.

Zwier, J., Blok, V., \& Lemmens, P. (2016). Phenomenology and the empirical turn: A phenomenological analysis of postphenomenology. Philosophy and Technology. https://doi.org/10.1007/s13347-016-0221-7.

Zwier, J., Blok, V., Lemmens, P., \& Geerts, R. J. (2015). The ideal of a zero-waste humanity: Philosophical reflections on the demand for a bio-based economy. Journal of Agricultural and Environmental Ethics, 28(2), 353-374.

Publisher's Note Springer Nature remains neutral with regard to jurisdictional claims in published maps and institutional affiliations. 